\title{
Differentiation between Yeast Species, and Strains within a Species, by Cellular Fatty Acid Analysis. 2. Saccharomyces cerevisiae*
}

\author{
O.P.H. Augustyn \\ Submitted for publication: February 1989 \\ Accepted for publication: April 1989 \\ Keywords: Saccharomyces cerevisiae, yeasts, fatty acids, strain differentiation.
}

Viticultural and Oenological Research Institute (VORI), Private Bag X5026, 7600 Stellenbosch, Republic of South Africa.

\begin{abstract}
Fatty acid extracts of 50 Saccharomyces cerevisiae strains, grown under rigidly standardised conditions, were subjected to capillary gas chromatographic analysis on a polar column. Strains contained saturated, mono-unsaturated and trace amounts of dienoic fatty acids. The mean relative percentages of $\mathbf{1 0}$ fatty acids were used to differentiate between the strains studied. Forty-six strains could be differentiated from all others in the group, based on the criterion that when comparing two strains the CFAP's were considered unique if the MRP's of at least one fatty acid differed at the $1 \%$ level. Holman's Index of Relationship proved to be a useful tool for indicating degree of similarity between fatty acid profiles.

Efforts to distinguish between the species Sacch. cerevisiae and Sacch. bayanus were not successful. More analyses on authentic strains (determined by DNA homology) are necessary to confirm whether such a separation is possible or not.

Oenologically important changes that occurred in a commercial dried yeast during production were reflected in the fatty acid profiles of the dried products. Index of Relationship between the fatty acid profiles of five other dried yeast products, and the mother cultures from which they were produced, was very high indicating no change during the commercial production phase. Changes, or lack of change, were confirmed by fermentation studies.
\end{abstract}

South African wine-makers rely almost exclusively on selected strains of Saccharomyces cerevisiae, in the active dried form, to convert must to wine. Over the last decade the local industry has experienced recurrent stuck/lagging fermentation problems resulting in serious cellar capacity problems during the harvest as well as financial losses due to reduction in wine quality. A number of factors contributing to this problem have been identified to date. These include a too low level of assimilable nitrogen (Vos, Zeeman \& Heymann, 1978), insufficient levels of grape solids (Groat \& Ough, 1978; Houtman \& Du Plessis, 1981), a too low fermentation temperature (Tromp, 1984) and the action of killer yeasts (Tredoux, Tracey \& Tromp, 1986; Van Vuuren \& Wingfield, 1986).

The inability of classical taxonomic techniques to characterise yeast strains hampers the resolution of the stuck fermentation problem as it is never clear whether the yeast strain inoculated in a particular must is the same as the dominant yeast present upon completion of fermentation. Against this background the development of a yeast strain characterisation technique was identified as a research priority by leaders of the local wine industry.

Augustyn \& Kock (1989) indicated that it was possible to differentiate between 13 strains of Sacch. cerevisiae by means of cellular fatty acid analysis (CFAA). This paper explores the utility of the technique when a large number of strains have to be differentiated. The technique was also applied to fatty acid extracts from six dried yeast preparations, and the respective mother cultures from which they were prepared, in an effort to detect possible changes induced by the commercial production and drying processes.

\section{MATERIALS AND METHODS}

\section{Organisms studied}

The fifty Sacch. cerevisiae strains used in this study are listed in Table 1. Stock cultures were maintained on YM agar slants. In addition the mother cultures of six commercial strains, viz. N6 (WE 14), N66 (WE 372), N76 (228), N93 (WE 500), N95 and N96 (maintained under liquid $\mathrm{N}_{2}$ at the VORI) were used to compare their fatty acid profiles with the profiles of the corresponding dried yeast products.

\section{Cultivation of organisms}

Organisms were cultivated according to the method described by Augustyn \& Kock (1989). Culture medium consisted of $6,7 \mathrm{~g} / \mathrm{l}$ yeast nitrogen base (Difco) and $80 \mathrm{~g} / \mathrm{l}$ glucose. Organisms were cultivated on a rotary shaker at $30^{\circ} \mathrm{C}$ in conical flasks equipped with a sidearm to facilitate direct reading in a Klett apparatus equipped with a $640 \mathrm{~nm}$ filter. Cultivation proceeded in two stages. The preculture consisted of $40 \mathrm{ml}$ culture medium ( $250 \mathrm{ml}$ flask) and organisms were cultivated for $16 \mathrm{~h}$ (Klett 190 - 200 minimum). Slow-growing organisms were maintained in the preculture until the required Klett reading was reached. Some organisms failed to reach the required Klett reading and these were harvested in the stationary phase. For the final culture, $10 \mathrm{ml}$ of the preculture was added to $300 \mathrm{ml}$ culture medium in a 1 litre flask. Cultivation then proceeded for two days or until the organism reached stationary phase in the case of very slow growers. Cells were harvested by centrifugation at $8000 \mathrm{~g}$ for $15 \mathrm{~min}$ at $4^{\circ} \mathrm{C}$ and the sediment washed once with cold saline so-

\footnotetext{
* Part of work to be presented as a Ph.D thesis to the University of the Orange Free State, Promoter dr. J.L.F. Kock.

Presented in part at the 12th congress of the SASEV, Cape Town, November 2-3, 1988.

Acknowledgements: H.G. Tredoux is thanked for fruitful discussions and advice, L. Fourie and ms C.A. le Roux for excellent technical assistance, B. Lötter and T.R. Potgieter for computer analyses.
} 
TABLE 1. Saccharomyces cerevisiae strains studied

\begin{tabular}{|c|c|}
\hline $\begin{array}{c}\text { VORI } \\
\text { Collection no. }\end{array}$ & ADDITIONAL INFORMATION \\
\hline N1 & - \\
\hline $\mathrm{N} 2$ & Elsenburg N \\
\hline N3 & Elsenburg Q \\
\hline N4 & K 35 \\
\hline N5 & D. 48 (a) 1 \\
\hline N7 & K.W.V. 19(b) \\
\hline N8 & K.W.V. white \\
\hline N9 & Champ. Hautvilliers \\
\hline N10 & $N-27 a$ \\
\hline N11 & $\mathrm{N}-33$ \\
\hline N12 & N-58a \\
\hline N13 & $\mathrm{K}-13$ \\
\hline N14 & $\mathrm{K}-14$ \\
\hline N16 & K.W.V. 14 \\
\hline N17 & K.W.V. 28 \\
\hline N18 & $\mathrm{K}-19 \mathrm{a}$ \\
\hline N19 & D $48 \mathrm{cl}$ \\
\hline N23 & $\mathrm{N}-3$ \\
\hline N29 & K.W.V. 60 \\
\hline N71 & Epernay; Sacch. uvarum* \\
\hline N72 & C.B.S 435; ex Sake-moto \\
\hline N73 & CBS 1598; Sacch. cerevisiae \\
\hline N77 & $\begin{array}{l}\text { D.G.I. } 243 \text {; Danish red wine - tannin resistant } \\
\text { Sacch. cerevisiae* }\end{array}$ \\
\hline N78 & D.G.I. 259 ; desert wine $73 \%$ sugar tolerant \\
\hline N81 & STV 142; INRA, Dijon, France \\
\hline N83 & $\mathrm{S} 47 \mathrm{c}$ \\
\hline N85 & S 46c \\
\hline N86 & STV 142; INRA, Dijon, France, May 1982 \\
\hline N87 & Eg 16; INRA, Colmar, France. May 1982 \\
\hline N88 & Eg 8; INRA, Colmar, France. May 1982 \\
\hline N89 & OC \# 2 ex Goto; Yamanishi Univ. Kikkoman \\
\hline N90 & W - 3 ex Goto; Yamanishi Univ, Kikkoman \\
\hline N92 & Red Star Champagne \\
\hline N97 & Wädenswil 27 \\
\hline N98 & 71B; INRA, Narbonne, France \\
\hline N100 & SAF OENOS \\
\hline N101 & $\begin{array}{l}\text { SB - } 1 \text { (Lalvin 1119); Sacch. bayanus, INRA, } \\
\text { Montpellier, start stuck fermentation. }\end{array}$ \\
\hline N102 & CBS $1171 ;$ Sacch. cerevisiae* (Type) \\
\hline N103 & CBS 380; Sacch. bayanus (Type) \\
\hline N104 & NCYC \# 738 \\
\hline N105 & NCYC \# 1006 \\
\hline N110 & CSIR - Y2 \\
\hline N111 & CSIR - Y31 \\
\hline N117 & CBS 380; Sacch. bayanus (Type) \\
\hline N118 & CBS 400; Sacch. chevalieri \\
\hline N131 & CBS 4054; Sacch. aceti* \\
\hline N161 & CSIR - Y106 \\
\hline N180 & SIHA 1, Sacch. cerevisiae* \\
\hline $\mathrm{N} 234$ & CBS 5155; Sacch. prostoserdovii \\
\hline N237 & CBS 6413; Sake yeast \\
\hline
\end{tabular}

${ }^{*}$ Confirmed to be Sacch. cerevisiae by J.P. van der Walt (CSIR, Division of Food Science and Technology, Pretoria, Republic of South Africa).

lution. After centrifugation the recovered cells were lyophilised and stored in glass bottles in a dessicator at $-8^{\circ} \mathrm{C}$ to $-10^{\circ} \mathrm{C}$.

In a modification of the cultivation method described above, fresh slants were prepared from the stock cultures four days before strains were inoculated into the preculture. These fresh slants were maintained at $30^{\circ} \mathrm{C}$. The effect of this modification on the growth and fatty acid mean relative percentages was monitored for a number of strains. Duplicate cultivations of four strains were made 30 days after initial cultivation to determine repeatability of the method over time.

Commercial dried yeasts were rehydrated in water at $37^{\circ} \mathrm{C}$ and then streaked out onto malt extract agar. After incubation at $30^{\circ} \mathrm{C}$, single uniform colonies were streaked out on YM agar slants. These slants were used as above to prepare material for fatty acid analysis. Rehydrated dried yeasts, and yeasts from the respective mother cultures of N93 and N96, were also inoculated into Chenin blanc and Morio Muscat musts. Fermentation rate was monitored by measuring $\mathrm{CO}_{2}$ loss.

\section{Sporulation of some commercial yeast strains}

Strains N6, N93, N95 and N96 (from the respective mother cultures) were inoculated into a pre-sporulation medium consisting of $50 \%$ must/water. After $48 \mathrm{~h}$ at $25^{\circ} \mathrm{C}$ a light inoculum was streaked out onto McLeary's Acetate medium and the slants incubated at $20-25^{\circ} \mathrm{C}$. Some strains needed up to 30 days to reach a high percentage sporulated cells. The whole sporulated mass was transferred to the standard preculture medium to simulate the fate of sporulated material that possibly appeared during the commercial preparation of dried yeast and cultivation proceeded as above. A second preculture was prepared from the first in order to give the yeasts more time to stabilise their fatty acid profiles and cultivation proceeded as described.

\section{Fatty acid extraction and preparation of methyl esters}

Esters were prepared by the method of Augustyn \& Kock (1989). Briefly; dried cells $(0,120 \mathrm{~g})$ were saponified with $2,5 \% \mathrm{KOH}$ in $50 \%$ methanol/water. Non-saponifiable material was extracted with 1:4 chloroform/hexane and the aqueous layer acidified to $\mathrm{pH} 2$. Free acids were extracted with 1:4 chloroform/hexane, the solvent evaporated under $\mathrm{N}_{2}$ and the acids esterified with $20 \%$ boron trifluoride-methanol. The methyl esters were extracted with 1:4 chloroform/hexane and the extracts dried over anhydrous $\mathrm{MgSO}_{4}$ prior to concentration and analysis.

Possible losses of fatty acid material during the first extraction step (removal of non-saponifiable material) were examined by excluding this step in the preparation of esters from a number of organisms. Fatty acid profiles from these extracts were then compared with profiles generated from extracts prepared by the original technique.

\section{Gas chromatography and mass spectrometry}

Fatty acids extracts were analysed by gas chromatography on a J \& W DB wax capillary column (30 m x $0,32 \mathrm{~mm}$ I.D., coating 0,15 micron) and identified by analysis of methyl and picolinyl esters (Augustyn \& Kock, 1989).

Throughout this paper fatty acids were named according to the delta system in which the carboxyl carbon atom is designated number one. Abbreviated fatty acid notation, eg. C 16:1(9), designates; number of carbon atoms, number of double bonds (position of double bond $[\mathrm{s}])$.

\section{Differentiation between organisms by comparison of fatty acid relative percentages}

The relative percentages of 10 fatty acids, viz. C14:0, C14:1(9), C15:0, C15:1(9), C16:0, C16:1(9), C16:1(11), C18:0, C18:1(9) and C18:1(11), were used to differentiate between the strains studied. Raw data (quadruplicates) were subjected to a two-way analysis of variance and mean relative percentages differing at 
the $1 \%$ level used to differentiate between strains.

The relatedness of any two strains was computed by applying the formula developed by Holman (1978):

$R x, y=\left(\frac{C x}{C y}\right)_{1}\left(\frac{C x+C y}{200}\right)_{1}+\cdots+\left(\frac{C x}{C y}\right)_{n}\left(\frac{C x+C y}{200}\right)_{n}$

In this formula $\mathrm{R}$ represents the Index of Relationship, $\mathrm{x}$ and $\mathrm{y}$ are the two strains being compared, $\mathrm{C}$ is the concentration expressed as a relative percentage and 1 through $\mathrm{n}$ are the fatty acids used to differentiate between the strains ( $\mathrm{n}=10$ in this instance). It is important to note that $\frac{C x}{C y}$ represents the minor ration of the particular fatty acid in the two strains.

\section{RESULTS AND DISCUSSION}

\section{Fatty acids of Saccharomyces cerevisiae}

For the purposes of this general discussion the epithet Sacch. cerevisiae was applied as in Yarrow (1984). Fatty acids containing more than 18 carbon atoms were not considered in this study. The fourteen fatty acids identified in this study, viz. C12:0, C14:0, C14:1(9), C15:0, C15:1(9), C16:0, C16:1(9), C16:1(11), C17:0, C17:1(9), C17:1(11), C18:0, C18:1(9) and C18:1(11), corresponded to those identified by Augustyn \& Kock (1989). Some strains also contained C17:1(8) tentatively identified by these authors.

Fragmentary mass spectral data indicated the presence of trace amounts of dienoic fatty acids (C16:2 and/or C18:2) in some of the strains. No trace of polyunsaturated fatty acids was detected in any of the strains. Three of the four cultures of strain N131 contained a larger amount of C18:2 (retention time, methyl ester mass spectrum: $\mathbf{M}^{+} 294$, base peak $\mathrm{m} / \mathrm{z}$ 67). The absence of $\mathrm{C} 18: 2$ in the fourth sample coupled to the large variation in the relative percentage $\mathrm{C} 18: 2$ recorded in the other three cultures $(0,199 \%, 0,315 \%$ and $0,542 \%$ ), cast doubt on the origin of this C18:2. Strain N131 was examined by J.P. van der Walt (CSIR, Division of Food Science and Technology, Pretoria, Republic of South Africa) and subjected to standard taxonomic tests. It was determined as a strain of Sacch. aceti Santa Maria (= Sacch . cerevisiae sensu Yarrow). This strain will be re-examined and other authentic strains of Sacch. aceti acquired to clarify the position regarding the presence or absence of significant amounts of C18:2 in these strains. Baraud, Maurice \& Napias (1970) reported the presence of, amongst others, C12:2, C16:3 and C18:3 in the cellular fatty acid profile (CFAP) of Sacch. cerevisiae strain $\mathrm{S}_{2}$ (Springer), while Bulder \& Reinink (1974) reported C18:2 and C18:3 in a number of Sacch. cerevisiae strains including strain CBS 380. Malfeito - Ferreira, Fonseca \& Loureiro (1987) distinguished between Sacch. cerevisiae (strains IGC 4072 \& IGC 4074) and Torulaspora delbrueckii (strain IGC 4269 ) by means of the lower relative percentage C16:1 and higher relative percentage C18:2 in the latter organism. On the other hand Kock, Cottrell \& Lategan (1986), Tredoux, Kock \& Lategan (1987) and Augustyn \& Kock (1989) found no trace of dienoic fatty acids in various strains of Sacch. cerevisiae. Reasons for these discrepant results are not apparent.

\section{Fatty acid relative percentages}

The mean relative percentages (MRP's) for the 10 fatty acids used for strain differentiation are listed in
Table 2. Maximum and minimum values for each fatty acid are printed in bold type. It is clear that these relative percentages vary widely. These variations were of the same order as those reported by Ribes et al. (1988) for 6 fatty acids in 18 Sacch. cerevisiae strains. Saccharomyces cerevisiae as defined by Yarrow (1984) is a heterogeneous species and it is extremely unlikely that analysis of the fatty acid profiles of a limited number of strains would allow the analyst to gauge accurately the variation in fatty acid MRP's occurring within the species. Kock et al. (1986) determined the fatty acids in four strains of Sacch. cerevisiae and used the MRP's to differentiate that species from others within the genus Saccharomyces. Applying the parameters set down in that study to the data presented in Table 2, would result in many strains not being recognised as belonging to Sacch. cerevisiae.

Tredoux et al. (1987) studied the CFAP's of 41 strains of Sacch. cerevisiae, many of which were also included in this study. Their results, generated on packed columns, also showed a large variation in fatty acid MRP's for the various strains, but were limited to data for six fatty acids because of the poor resolution obtained on the packed columns. A comparison of the data generated by Tredoux et al. (1987), and those obtained in this study, is made in Table 3. Data for C16:1(9)/C16:1(11) and C18:1(9)/C18:1(11) generated here were combined and expressed as C16:1 and C18:1 to conform with data from Tredoux et al. (1987). The sharper peaks generated by capillary gas chromatographic analysis resulted in more accurate integration of minor fatty acid peaks and could account for the variations noted for the MRP's of C14:0 and C14:1. Perusal of the data for individual and total $\mathrm{C} 18$ acids revealed differences that were not easily explained. As the same culture medium and general cultivation conditions were used in both studies, almost identical values for the MRP's of the major fatty acids should have been obtained. Augustyn \& Koch (1989) pointed out that the esterification procedure used by Tredoux et al. (1987) did not affect complete esterification. If this incomplete esterification distorted the natural ratio of $\mathrm{C} 16$ and $\mathrm{C} 18$ acids found in the various strains and left relatively more free $\mathrm{C} 16: 1$ acid in the extract, it could well be the cause of the elevated C18:1 MRP's reported by Tredoux et al. (1987).

\section{Differentiation between strains based on fatty acid mean relative percentages}

The strains studied here represent only 48 different organisms as N81/N86 and N103/N117 respectively represent two isolates of the same organisms (Table 1). Statistical analysis revealed that 46 of the strains had unique fatty acid profiles that distinguished each strain from the others (Augustyn \& Kock, 1989). When comparing two strains the CFAP's were considered unique if the MRP's of at least one fatty acid differed at the $1 \%$ level. Comparisons can be made by utilising the MRP's and D-values presented in Table 2.

This strain differentiation criterion must, however, be applied with discression. If two strains were distinguished by the MRP's of one or two fatty acids that exceed the limits for similarity, as determined by the D value, by a very small margin, the differentiation must be considered doubtful. The situation could very easily 
TABLE 2. Mean Relative Percentage (MRP) of 10 fatty acids in 50 strains of Saccharomyces cerevisiae.

\begin{tabular}{|c|c|c|c|c|c|c|c|c|c|c|}
\hline \multirow{2}{*}{$\begin{array}{l}\text { Yeast } \\
\text { Strain }\end{array}$} & \multicolumn{10}{|c|}{$\begin{array}{c}\text { Fatty acid } \\
\text { (MRP) }\end{array}$} \\
\hline & C14:0 & $\mathrm{C} 14: 1(9)$ & $\mathrm{C} 15: 0$ & C15:1(9) & $\mathrm{C} 16: 0$ & C16:1(9) & C16:1(11) & C18:0 & C18:1(9) & C18:1(11) \\
\hline 1 & 1,264 & 0,618 & 0,180 & 0,183 & 8,315 & 48,091 & 0,407 & 4,959 & 34,322 & 1,160 \\
\hline $\mathrm{N} 2$ & 0,929 & 0,367 & 0,182 & 0,188 & 7,880 & 44,306 & 0,338 & 4,951 & 38,656 & 1,442 \\
\hline N 3 & 1,201 & 0,611 & 0,228 & 0,220 & 8,272 & 46,865 & 0,425 & 5,545 & 34,343 & 1,776 \\
\hline N 4 & 1,241 & 0,813 & 0,121 & 0,199 & 6,378 & 47,733 & 0,444 & 4,568 & 36,486 & 1,519 \\
\hline N 5 & 1,944 & 0,515 & 0,309 & 0,117 & 16,440 & 41,825 & 0,195 & 3,041 & 34,074 & 1,223 \\
\hline N 7 & 0,687 & 0,256 & 0,173 & 0,209 & 6,038 & 48,766 & 0,464 & 5,249 & 34,564 & 2,818 \\
\hline N 8 & 1,376 & 1,077 & 0,134 & 0,237 & 6,594 & 47,470 & 0,536 & 5,103 & 36,092 & 0,949 \\
\hline $\mathrm{N} 9$ & 0,707 & 0,269 & 0,136 & 0,144 & 8,213 & 46,809 & 0,410 & 4,970 & 35,939 & 1,835 \\
\hline N 10 & 1,060 & 0,193 & 0,615 & 0,171 & 16,399 & 37,079 & 0,193 & 2,862 & 39,256 & 1,609 \\
\hline N 11 & 1,934 & 0,880 & 0,172 & 0,178 & 11,067 & 49,612 & 0,439 & 3,842 & 30,252 & 1,245 \\
\hline N 12 & 1,400 & 0,606 & 0,323 & 0,330 & 10,367 & 50,813 & 0,491 & 4,262 & 29,189 & 1,648 \\
\hline N 13 & 1,226 & 1,084 & 0,256 & 0,385 & 5,902 & 53,530 & $\mathbf{0 , 7 6 3}$ & 4,550 & 30,147 & 1,685 \\
\hline N 14 & 1,031 & 0,488 & 0,180 & 0,209 & 7,191 & 47,580 & 0,458 & 5,552 & 34,929 & 1,796 \\
\hline N 16 & 1,842 & 1,031 & 0,158 & 0,222 & 8,552 & 50,382 & 0,441 & 3,858 & 31,390 & 1,528 \\
\hline N 17 & 2,153 & 0,746 & 0,245 & 0,205 & 15,691 & 46,491 & 0,174 & 6,441 & 26,336 & 1,046 \\
\hline N 18 & 1,192 & 0,370 & 0,151 & 0,122 & 12,380 & 45,525 & 0,389 & 5,016 & 32,884 & 1,442 \\
\hline N 19 & 0,799 & 0,581 & 0,211 & 0,328 & 5,833 & 47,352 & 0,614 & 5,102 & 35,942 & 2,208 \\
\hline N 23 & 1,111 & 0,536 & 0,181 & 0,195 & 8,961 & 47,220 & 0,375 & 6,531 & 32,812 & 1,614 \\
\hline N 29 & 1,657 & 0,757 & 0,187 & 0,204 & 11,332 & 51,615 & 0,518 & 4,001 & 27,820 & 1,367 \\
\hline N 71 & $\mathbf{3 , 3 6 7}$ & 0,756 & 0,144 & 0,070 & 24,329 & 43,636 & 0,047 & 3,489 & 23,191 & 0,612 \\
\hline N 72 & 0,413 & 0,413 & 0,234 & 0,321 & 8,298 & 45,404 & 0,404 & 7,979 & 32,713 & 2,805 \\
\hline N 73 & 0,585 & 0,723 & 0,100 & 0,315 & 5,719 & 55,916 & 0,537 & 3,144 & 29,507 & 2,696 \\
\hline N 77 & 0,750 & 0,309 & 0,182 & 0,189 & 6,970 & 36,629 & 0,169 & 6,364 & 46,880 & 0,770 \\
\hline N 78 & 0,643 & 0,257 & 0,264 & 0,238 & 9,056 & 44,265 & 0,394 & 6,194 & 36,282 & 1,557 \\
\hline N 81 & 1,305 & 0,187 & 0,377 & 0,124 & 17,750 & 36,845 & 0,142 & 3,052 & 38,209 & 1,619 \\
\hline N 83 & 2,181 & 0,550 & 0,343 & 0,158 & 16,317 & 36,388 & 0,151 & 5,200 & 37,374 & 0,934 \\
\hline N 85 & 1,056 & 0,352 & 0,173 & 0,162 & 11,198 & 47,243 & 0,332 & 4,319 & 33,054 & 1,703 \\
\hline N 86 & 1,118 & $\mathbf{0 , 1 5 8}$ & 0,378 & 0,101 & 18,338 & 36,431 & 0,116 & 3,571 & 38,018 & 1,510 \\
\hline N 87 & 1,647 & 0,294 & 0,299 & 0,078 & 20,290 & 40,142 & 0,119 & 3,392 & 32,051 & 1,480 \\
\hline N 88 & 1,594 & 0,333 & 0,478 & 0,132 & 17,969 & 37,481 & 0,159 & 3,943 & 36,027 & 1,606 \\
\hline N 89 & 0,854 & 0,361 & 0,236 & 0,210 & 8,315 & 42,069 & 0,357 & 6,538 & 38,859 & 1,482 \\
\hline N 90 & 1,230 & 0,686 & 0,169 & 0,226 & 7,810 & 43,959 & 0,309 & 5,991 & 37,907 & 1,150 \\
\hline N 92 & 1,324 & 0,278 & 0,410 & 0,114 & 18,870 & 37,784 & 0,136 & 4,031 & 35,356 & 1,315 \\
\hline N 97 & 1,985 & 1,320 & 0,321 & 0,326 & 9,296 & 44,985 & 0,361 & 5,152 & 34,331 & 1,227 \\
\hline N 98 & 1,025 & 0,561 & 0,148 & 0,192 & 7,606 & 45,297 & 0,430 & 5,484 & 36,869 & 1,789 \\
\hline N100 & $\mathbf{0 , 3 9 7}$ & 0,169 & 0,389 & 0,363 & 6,064 & 45,371 & 0,285 & 7,474 & 36,308 & 1,997 \\
\hline N101 & 0,527 & 0,226 & 0,289 & 0,273 & 7,729 & 42,360 & 0,253 & 5,791 & 39,886 & 1,865 \\
\hline N102 & 1,304 & 0,633 & 0,057 & 0,062 & 12,198 & 38,306 & 0,225 & 7,709 & 38,480 & $\mathbf{0 , 5 7 8}$ \\
\hline N103 & 1,608 & 0,351 & 0,476 & 0,186 & 20,496 & 47,163 & 0,070 & 3,394 & 25,119 & 0,879 \\
\hline N104 & 0,912 & 0,253 & 0,265 & 0,151 & 14,452 & 39,456 & 0,206 & 6,816 & 35,025 & 1,707 \\
\hline N105 & 0,606 & 0,218 & 0,075 & 0,095 & 9,042 & 37,944 & 0,235 & 5,680 & 44,685 & 1,008 \\
\hline N110 & 0,608 & 0,446 & 0,344 & 0,418 & 7,692 & 47,253 & 0,343 & 5,503 & 34,305 & 2,118 \\
\hline N111 & 0,661 & 0,395 & 0,415 & 0,488 & 8,666 & 45,699 & 0,276 & 6,447 & 33,837 & 1,936 \\
\hline N117 & 1,405 & 0,242 & 0,628 & 0,227 & 20,131 & 47,234 & 0,057 & 3,274 & 25,368 & 0,880 \\
\hline N118 & 1,325 & 0,629 & 0,185 & 0,230 & 9,100 & 48,066 & 0,354 & 4,413 & 33,964 & 1,257 \\
\hline N131 & 1,272 & 0,218 & 0,745 & 0,218 & 20,935 & 34,517 & 0,141 & 5,562 & 34,155 & 0,983 \\
\hline N161 & 2,925 & 1,693 & 0,603 & $\mathbf{0 , 9 3 9}$ & 14,473 & 49,080 & 0,592 & 3,066 & 23,863 & 0,948 \\
\hline N180 & 0,732 & 0,387 & 0,168 & 0,206 & 5,939 & 43,783 & 0,442 & 6,448 & 39,246 & 1,760 \\
\hline N234 & 1,422 & 0,335 & 0,309 & 0,169 & 17,360 & 42,887 & 0,205 & 2,497 & 33,348 & 1,139 \\
\hline $\mathrm{N} 237$ & 0,507 & 0,265 & 0,167 & 0,192 & 7,793 & 41,519 & 0,237 & 6,840 & 39,971 & 1,865 \\
\hline $\mathrm{D}(\mathrm{p} \leqslant 0,01)$ & 0,192 & 0,112 & 0,043 & 0,040 & 1,008 & 2,319 & 0,035 & 0,931 & 2,195 & 0,194 \\
\hline
\end{tabular}

Values printed in bold represent the minimum and maximum values for each fatty acid

TABLE 3. Comparison between the fatty acid relative percentages generated in this study and that of Tredoux et al. (1987).

\begin{tabular}{|c|c|c|c|c|c|c|c|c|}
\hline $\begin{array}{c}\text { Yeast } \\
\text { Strain }\end{array}$ & \multicolumn{9}{|c|}{$\begin{array}{c}\text { FATTY ACID } \\
\text { (relative \%) }\end{array}$} \\
\hline & C14:0 & C14:1 & C16:0 & C16:1 & C18:0 & C18:1 & Tot. C16 & Tot. C18 \\
\hline N5 T & 1,0 & 0,2 & 10,2 & 41,6 & 1,4 & 45,7 & 51,8 & 47,1 \\
P & 1,9 & 0,5 & 16,4 & 42,0 & 3,0 & 35,3 & 58,0 & 38,3 \\
N22 T & 0,4 & 0,07 & 8,1 & 35,8 & 1,7 & 53,8 & 43,9 & 55,5 \\
P* & 1,3 & 0,05 & 16,0 & 32,6 & 4,6 & 43,3 & 48,6 & 47,9 \\
N29 T & 1,2 & 0,6 & 7,7 & 49,4 & 2,5 & 38,6 & 57,1 & 41,1 \\
P & 1,7 & 0,8 & 11,3 & 52,1 & 4,0 & 29,2 & 63,4 & 33,2 \\
\hline
\end{tabular}

$\mathrm{T}=$ data generated by Tredoux et al. (1987).

$\mathrm{P}=$ data generated in present study, C16:1(9) + C16:1(11) and C18:1(9) + C18:1(11) combined as C16:1 and C18:1 respectively.

$\mathrm{P}^{*}$ strain not included in original study (Table 1), specially cultivated for comparative purposes. 
TABLE 4. Effect of the mean relative percentages (MRP's) of the major fatty acids on the Index of Relationship (R).

\begin{tabular}{|c|c|c|c|c|c|c|c|c|c|c|c|}
\hline \multirow[t]{2}{*}{$\begin{array}{l}\text { Yeast } \\
\text { Strain }\end{array}$} & \multicolumn{10}{|c|}{$\begin{array}{l}\text { FATTY ACID } \\
\text { (MRP) }\end{array}$} & \multirow[t]{2}{*}{$\mathrm{R}_{\mathrm{x}, \mathrm{y}}$} \\
\hline & C14:0 & C14:1(9) & C15:0 & C15:1(9) & C16:0 & C16:1(9) & C16:1(11) & C18:0 & C18:1(9) & C18:1(11) & \\
\hline $\begin{array}{l}\text { N103 (x) } \\
\text { N117 (y) }\end{array}$ & $\begin{array}{l}1,61 \\
1,41\end{array}$ & $\begin{array}{l}0,35 \\
0,24\end{array}$ & $\begin{array}{l}0,48 \\
0,63\end{array}$ & $\begin{array}{l}0,19 \\
0,23\end{array}$ & $\begin{array}{l}20,50 \\
20,13\end{array}$ & $\begin{array}{l}47,16 \\
47,23\end{array}$ & $\begin{array}{l}0,07 \\
0,06\end{array}$ & $\begin{array}{l}3,39 \\
3,27\end{array}$ & $\begin{array}{l}25,12 \\
25,37\end{array}$ & $\begin{array}{l}0,88 \\
0,88\end{array}$ & $0 \overline{983}$ \\
\hline $\begin{array}{l}\text { N } 81(x) \\
\text { N } 86(y)\end{array}$ & $\begin{array}{l}1,31 \\
1,12\end{array}$ & $\begin{array}{l}0,19 \\
0,16\end{array}$ & $\begin{array}{l}0,38 \\
0,38\end{array}$ & $\begin{array}{l}0,12 \\
0,10\end{array}$ & $\begin{array}{l}17,50 \\
18,34\end{array}$ & $\begin{array}{l}36,85 \\
36,43\end{array}$ & $\begin{array}{l}0,14 \\
0,12\end{array}$ & $\begin{array}{l}3,05 \\
3,57\end{array}$ & $\begin{array}{l}38,21 \\
38,02\end{array}$ & $\begin{array}{l}1,62 \\
1,51\end{array}$ & $0, \overline{977}$ \\
\hline $\begin{array}{l}\mathrm{N} 1(\mathrm{x}) \\
\mathrm{N} 118(\mathrm{y})\end{array}$ & $\begin{array}{l}1,26 \\
1,33\end{array}$ & $\begin{array}{l}0,62 \\
0,63\end{array}$ & $\begin{array}{l}0,18 \\
0,19\end{array}$ & $\begin{array}{l}0,18 \\
0,23\end{array}$ & $\begin{array}{l}8,32 \\
9,10\end{array}$ & $\begin{array}{l}48,09 \\
48,01\end{array}$ & $\begin{array}{l}0,41 \\
0,35\end{array}$ & $\begin{array}{l}4,96 \\
4,41\end{array}$ & $\begin{array}{l}34,32 \\
33,96\end{array}$ & $\begin{array}{l}1,16 \\
1,26\end{array}$ & $\overline{0,976}$ \\
\hline $\begin{array}{l}\text { N } 14(x) \\
\text { N } 98(y)\end{array}$ & $\begin{array}{l}1,03 \\
1,03\end{array}$ & $\begin{array}{l}0,49 \\
0,56\end{array}$ & $\begin{array}{l}0,18 \\
0,15\end{array}$ & $\begin{array}{l}0,21 \\
0,19\end{array}$ & $\begin{array}{l}7,19 \\
7,61\end{array}$ & $\begin{array}{l}47,58 \\
45,30\end{array}$ & $\begin{array}{l}0,46 \\
0,43\end{array}$ & $\begin{array}{l}5,55 \\
5,48\end{array}$ & $\begin{array}{l}34,93 \\
36,87\end{array}$ & $\begin{array}{l}1,80 \\
1,79\end{array}$ & $\overline{0,947}$ \\
\hline $\begin{array}{ll}\mathrm{N} & 2(\mathrm{x}) \\
\mathrm{N} & 3(\mathrm{y}) \\
\mathrm{N} & 8(\mathrm{y})\end{array}$ & $\begin{array}{l}0,93 \\
1,20 \\
1,38\end{array}$ & $\begin{array}{l}0,37 \\
0,61 \\
1,08\end{array}$ & $\begin{array}{l}0,18 \\
0,23 \\
0,13\end{array}$ & $\begin{array}{l}0,19 \\
0,22 \\
0,24\end{array}$ & $\begin{array}{l}7,88 \\
8,27 \\
6,59\end{array}$ & $\begin{array}{l}44,31 \\
46,87 \\
47,47\end{array}$ & $\begin{array}{l}0,34 \\
0,43 \\
0,54\end{array}$ & $\begin{array}{l}4,95 \\
5,55 \\
5,10\end{array}$ & $\begin{array}{l}38,66 \\
34,34 \\
36,09\end{array}$ & $\begin{array}{l}1,44 \\
1,78 \\
0,95\end{array}$ & $\begin{array}{l}-\overline{10} \\
0,910\end{array}$ \\
\hline $\mathrm{D}(\mathrm{p} \geqslant 0,01)$ & 0,192 & 0,112 & 0,043 & 0,040 & 1,008 & 2,319 & 0,035 & 0,931 & 2,195 & 0,194 & \\
\hline
\end{tabular}

be reversed after repeated cultivation and analysis of a new set of isolates. Strains N14/N98 and N81/N86 could not be differentiated whilst strains N103/N117, representing two isolates of the type strain of Sacch. bayanus, were differentiated by the MRP's of two fatty acids. The variations were small and the same argument as above may be valid in this case.

Large differences between the MRP's of all fatty acids were stable (Augustyn \& Kock, 1989) and could be used with confidence when differentiating between strains, even when a single fatty acid was involved.

\section{The Index of Relationship}

The Index of Relationship ( $\mathrm{R}$ ) for all possible combinations of the strains studied is presented in Addendum 1. Values for $R$ ranged from a minimum of $0,591\left[R_{N 71}\right.$, $\mathrm{N} 77$ ] to a maximim of $0,983\left[\mathrm{R}_{\mathrm{N} 103}, \mathrm{~N} 117\right]$. For $R_{\mathbf{x}, \mathbf{y}}=1$ strains $\mathrm{x}$ and $\mathrm{y}$ will have exactly the same MRP's for all the fatty acids used to determine the relationship.

The major fatty acids, C16:1(9) and C18:1(9), made by far the largest contribution to the value of $\mathrm{R}$. A high $\mathrm{R}(>0,960)$ is dependent on a small difference between the respective MRP's of these acids in the strains being compared, as is illustrated by the data in Table 4 . Note the $R_{N 1, N 118}(0,976)$ is greater than $R_{N 14, N 98}(0,947)$ although the latter strains could not be differentiated by comparing the MRP's of the 10 fatty acids used for differentiating between strains.

Some strains had the same $\mathrm{R}$ with a number of other strains. This did not mean that differentiation between such strains was impossible as is illustrated by the data for N2, N3 and N8 (Table 4). The minor fatty acids which contributed a minute proportion of $\mathrm{R}$ afforded easy differentiation between these strains (D-value Table 4). The $R$ values, therefore, offered an easy method for grouping yeast strains according to similarity of the respective fatty acid profiles, while final strain differentiation was afforded by considering the D-values and MRP's of all the fatty acids used to determine R.

\section{Differentiation between Saccharomyces cerevisiae and Saccharomyces bayanus by means of cellular fatty acid analysis}

Only one strain [N104] had a R greater than 0,900 with the type of Sacch. cerevisae [N102], while 33
TABLE 5. Similarity of each strain to all other strains in the group

\begin{tabular}{|c|c|c|c|}
\hline Strain & $\begin{array}{l}\text { Similarity to group } \\
\qquad\left(\varepsilon_{\underline{n}}\right)\end{array}$ & Strain & $\begin{array}{l}\text { Similarity to group } \\
\qquad\left(\varepsilon_{\underline{n}}\right)\end{array}$ \\
\hline $\mathrm{N} 3$ & 0,869 & N234 & 0,835 \\
\hline $\begin{array}{ll}\mathrm{N} & 9\end{array}$ & 0,867 & N104 & 0,832 \\
\hline N 1 & 0,865 & N 16 & 0,832 \\
\hline N118 & 0,864 & N237 & 0,829 \\
\hline N 98 & 0,864 & N 11 & 0,829 \\
\hline N 14 & 0,864 & N 12 & 0,818 \\
\hline N 97 & 0,863 & N 88 & 0,815 \\
\hline N 78 & 0,863 & N 92 & 0,814 \\
\hline N 85 & 0,862 & N102 & 0,813 \\
\hline N110 & 0,861 & N 87 & 0,809 \\
\hline N 23 & 0,861 & N 83 & 0,806 \\
\hline N 18 & 0,861 & N 17 & 0,806 \\
\hline N111 & 0,860 & N 81 & 0,800 \\
\hline N 8 & 0,858 & N 29 & 0,800 \\
\hline N 90 & 0,857 & N 86 & 0,798 \\
\hline N 4 & 0,857 & N 10 & 0,797 \\
\hline N 2 & 0,856 & N 13 & 0,794 \\
\hline N 19 & 0,852 & N105 & 0,782 \\
\hline N 7 & 0,845 & N117 & 0,780 \\
\hline N100 & 0,844 & N103 & 0,779 \\
\hline N 89 & 0,844 & N131 & 0,773 \\
\hline N 72 & 0,842 & N 73 & 0,760 \\
\hline N180 & 0,838 & N161 & 0,758 \\
\hline N 5 & 0,838 & N 77 & 0,749 \\
\hline N101 & 0,837 & N 71 & 0,730 \\
\hline
\end{tabular}

strains had a $\mathrm{R}$ greater than 0,800 (Addendum I). Two strains [N17, N117] had a R greater than 0,900 and 15 strains a R of greater than 0,800 with the type strain of Sacch. bayanus. Values expressing the similarity of each strain to the group as a whole $\left(\frac{\varepsilon_{R}}{n}\right)$ are presented in Table 5. Strain N3 exhibited the highest similarity to the group as a whole and a $\mathrm{R}$ greater than 0,900 with 21 of the 50 strains studied (Addendum I). This fact again illustrates the necessity of analysing a large number of strains when attempting species differentiation by means of CFAA. It also indicates that the type strain does not necessarily have a fatty acid profile closely related to the majority of strains of a particular species.

Yarrow (1984) considered Sacch. bayanus a synonym of Sacch. cerevisiae. Vaughan Martini \& Martini (1987), however, indicated that Sacch. cerevisiae should in fact be subdivided into three species, viz. Sacch. cerevisiae, Sacch. bayanus and Sacch. pastoria- 
nus. These authors also indicated that DNA homology was the only method that could distinguish between these species. No authenic strains of Sacch. pastorianus were included in this study and a definite statement on the fatty acid relative percentage ranges typical of Sacch. cerevisiae and Sacch. bayanus can, therefore, not be made.

Strain N234, an authentic strain of Sacch. prostoserdovii (CBS 5155), had a R of 0,841 with the type strain of Sacch. bayanus [N103] and a R of 0,816 with the type of Sacch. cerevisiae [N102] (Addendum I). Saccharomyces prostoserdovii, a synonym of Sacch. cerevisiae (Yarrow, 1984), exhibited a 96\% DNA reassociation with the type strain of Sacch. cerevisiae (Vaughan Martini \& Kurtzman, 1985). The R between N234 and N3 was 0,846 , slightly higher than its $\mathrm{R}$ with Sacch. bayanus. Although Sacch. bayanus and Sacch. cerevisiae are genetically unrelated (Vaughan Martini \& Martini, by omitting this step during esterification of fatty acids from five strains. The $\mathrm{R}$ between these respective profiles and the profiles of duplicate esterifications which included the step removing the non-saponifiable material, indicated that a very small amount of CFA material, if any, was lost during removal of the non-saponifiable material (Table 6). The step was, therefore, retained to obtain cleaner samples.

\section{Effect of the commercial drying process on the fatty acid profile of six commercial yeast strains}

Local commercial dried yeast products were prepared from mother cultures maintained under liquid $\mathrm{N}_{2}$ at the VORI. For five of the six commercial products there was a high $\mathrm{R}$ between the mother cultures and the appropriate dried yeasts (Table 7 ). The low $\mathrm{R}$ recorded for the two batches of N93 (WE 500) resulted from pro-

TABLE 6. Effect of cultivation method, time between duplicate cultivations and esterification technique on the Index of Relationship (R) for selected strains of Saccharomyces cerevisiae

\begin{tabular}{|c|c|c|c|}
\hline \multirow{2}{*}{$\begin{array}{l}\text { Yeast } \\
\text { Strain }\end{array}$} & \multicolumn{3}{|c|}{$\mathrm{R}_{\mathrm{x}, \mathrm{y}}$} \\
\hline & $\begin{array}{l}\text { Cultivation } \\
\text { Method } \\
\text { (old/new) }\end{array}$ & $\begin{array}{l}\text { Time between cultivations } \\
\text { (new method/ } 30 \text { days later) }\end{array}$ & $\begin{array}{l}\text { Esterification } \\
\text { non-saponifiable } \\
\text { (in/out) }\end{array}$ \\
\hline $\begin{array}{l}\text { N1 } \\
\text { N2 } \\
\text { N5 } \\
\text { N7 } \\
\text { N11 } \\
\text { N72 } \\
\text { N77 }\end{array}$ & $\begin{array}{c}0,965 \\
0,957 \\
0,822 \\
0,944 \\
- \\
0,946 \\
0,908\end{array}$ & $\begin{array}{c}0,973 \\
0,969 \\
0,931 \\
0,964 \\
- \\
- \\
-\end{array}$ & $\begin{array}{c}0,989 \\
0,988 \\
- \\
- \\
0,977 \\
0,958 \\
0,983\end{array}$ \\
\hline
\end{tabular}

1987), Bousfield et al. (1983) pointed out that there was no fundamental reason why taxonomically very different organisms should not have similar fatty acid compositions. These results, therefore, indicate either that Sacch. cerevisiae and Sacch. bayanus cannot be differentiated by CFAA or that the R manipulates the fatty acid data in such a way that the differences that do exist are not exploited. An attempt at resolving these questions will be made in future work by utilising all the strains studied in the DNA homology work of Vaughan Martini \& Kurtzman (1985) and Vaughan Martini \& Martini (1987) and a variety of data manipulation techniques.

Effect of technique modification and time elapsed between successive cultivations of the same strain, on the cellular fatty acid profile of selected strains of Saccharomyces cerevisiae

Streaking out fresh isolates from the stock cultures four days before inoculation into the preculture resulted in faster growth of many cultures. Although some slight variations were apparent amongst the minor fatty acid relative percentages, the high $\mathrm{R}$-values (Table 6) indicated that the adapted cultivation method had a very small effect on the CFAP's of the yeasts examined. Reasons for the low $\mathrm{R}$ for N5 (old/new) were not apparent but it should be mentioned that the first cultivation (old method) was made at the onset of this study when methods were not as accurate as at the present time. All strains were subsequently cultured by the adapted method.

The potential loss of CFA's from the sample during removal of the non-saponifiable material was examined
TABLE 7. Index of Relationship ( $R$ ) between mother culture and the active dried yeast produced from that culture

\begin{tabular}{|l|c|}
\hline \multicolumn{1}{|c|}{$\begin{array}{c}\text { Saccharomyces cerevisiae } \\
\text { strain no. }\end{array}$} & $\mathrm{R}$ \\
\hline N6 (WE 14)* & 0,954 \\
N66 (WE 372) & 0,968 \\
N76 (228) & 0,987 \\
N93 (WE 500) Batch 6/1988 & 0,804 \\
N93 (WE 500) Batch 7/1988 & 0,820 \\
N95 & 0,972 \\
N96 & 0,947 \\
\hline
\end{tabular}

* Common names used by industry

nounced changes in the MRP's of three major fatty acids, eg:

$\begin{array}{lrll} & \text { C16:0 } & \text { C16:1(9) } & \text { C18:1(9) } \\ \text { N93 (mother culture) } & 17,12 \% & 38,12 \% & 36,13 \% \\ \text { N93 (dried, batch 6) } & 7,01 \% & 40,11 \% & 43,54 \%\end{array}$

Dramatic changes also occurred in the MRP's of some of the minor fatty acids but these changes would not have had a significant effect on the value of $R$. The reason for these changes was not apparent. It seems highly unlikely that the manufacturer would experience almost identical contamination problems during the preparation of only these two batches of dried material.

The yeast strains used by the local wine industry are all genetically unstable and sporulate very easily (I.S. Pretorius - lecture presented to the S.A.S.E.V. congress - November 1987). The effect of sporulation on the fatty acid profile of four commercial yeasts was studied by comparing the fatty acid profiles of sporulated 
material to those of the respective mother cultures. It is clear that for all strains the fatty acid profiles of the whole sporulated mass differed very little from the pro-

TABLE 8. Index of Relationship (R) between sporulated and nonsporulated (mother cultures) material of Saccharomyces cerevisiae for two cultivation procedures

\begin{tabular}{|l|r|c|c|}
\hline & & \multicolumn{2}{|c|}{ Cultivation Procedure } \\
\cline { 3 - 4 } Yeast & Degree of & & \\
Strain & Sporulation & Normal & $\begin{array}{c}\text { Additional } \\
\text { Preculture }\end{array}$ \\
& $\%$ & $\mathrm{R}_{\text {Mother/sporulated }}$ & $\mathrm{R}_{\text {Mother/sporulated }}$ \\
\hline N6 & 90 & 0,917 & 0,919 \\
N93 & 10 & 0,941 & 0,957 \\
& $>90$ & 0,954 & 0,940 \\
N95 & 5 & 0,952 & 0,919 \\
& $>90$ & 0,956 & 0,942 \\
N96 & 90 & 0,965 & 0,962 \\
\hline
\end{tabular}

file of the respective mother cultures (Table 8). Sporulation was, therefore, an unlikely cause of the changes noted in the fatty acid profiles of the dried batches of N93 (Table 7).

To determine if the changes recorded in the CFAP of the dried N93 had any oenological significance, fermentation studies were conducted using mother cultures and respective dried yeasts of two strains. While the fermentation curves for mother culture and dried N96 were indistinguishable, the dried batches of N93 clearly had inferior fermentation characteristics as the fermentation showed serious lagging (data not shown).

\section{CONCLUSIONS}

The variations in fatty acid relative percentages occurring in different strains of Sacch. cerevisiae could be reproduced reliably. These variations made reliable differentiation between strains possible. Differentiation was based on the MRP's of 10 fatty acids. As the number of strains to be characterised rises, problems may arise concerning the differentiation between closely related strains. Incorporation of additional fatty acids into the data base should help to alleviate this problem.

Additional authentic strains of Sacch. bayanus and Sacch. cerevisae must be analysed to determine if differentiation by CFAA is possible. Strains of Sacch. pastorianus must be included in such a study.

While it is unlikely that all oenologically important changes to a yeast strain will be reflected in its fatty acid profile, CFAA nevertheless adds a useful additional technique to the series of tests used to monitor the quality of the dried product.

\section{LITERATURE CITED}

AUGUSTYN, O.P.H. \& KOCK, J.L.F., 1989. Differentiation of yeast species, and strains within a species, by cellular fatty acid analysis. 1. Application of an adapted technique to differentiate between strains of Saccharomyces cerevisiae. J. Microbiol. Meth. (accepted for publication).

BARAUD, J., MAURICE, A. \& NAPIAS, C., 1970. Composition et répartition des lipides au sein des cellules de Saccharomyces cerevisiae. Bull. Soc. Chim. Biol. 52, $421-432$.

BOUSFIELD, I.J., SMITH, G.L., DANDO, T.R. \& HOBBS, G., 1983. Numerical analysis of total fatty acid profiles in the identification of Coryneform, Nocardioform and some other Bacteria. J. Gen. Microbiol. 129, $375-394$.

BULDER, C.J.E.A. \& REININK, M., 1974. Unsaturated fatty acid composition of wild type and respiratory deficient yeasts after aerobic and anaerobic growth. Antonie van Leeuwenhoek 40, 445 $-456$.

GROAT, M. \& OUGH, C.S., 1978. Effects of insoluble solids added to clarified musts on fermentation rate, wine composition and wine quality. Am. J. Enol. Vitic. 29, $112-119$.

HOLMAN, R.T., 1978. Quantitative chemical taxonomy based upon composition of lipids. Prog. Chem. Fats Lipids 16, 9-29.

HOUTMAN, A.C. \& DU PLESSIS, C.S., 1981. The effect of juice clarity and several conditions promoting yeast growth on fermentation rate, the production of aroma components and wine quality. S. Afr. J. Enol. Vitic. 2, 71-81.

KOCK, J.L.F., COTTRELL, M \& LATEGAN, P.M., 1986. A rapid method to differentiate between five species of the genus Saccharomyces. Appl. Microbiol. Biotechnol. 23, 499-501.

MALFEITO - FERREIRA, M., FONSECA, E. \& LOUREIRO, V., 1987. Rapid testing to differentiate between fermenting and spoilage yeasts in wine. 8th Congresso Nacional de Bioquimica. Póvoa de Varzim, Portugal. 28 November - 1 December 1987.

RIBES, P., NOMDEDEU, L., LAURICHESS, DOMINIQUE \& LEAUTE, R., 1988. Methodes statistique appliquees á la differenciation et la reconnaissance de souches de Saccharomyces cervisiae. Revue Francaise d'Oenologie 28, 35-42.

TREDOUX, H.G., KOCK, J.L.F. \& LATEGAN, P.M., 1987. The use of cellular long chain fatty acid composition in the identification of some yeasts associated with the Wine Industry. System. Appl. Microbiol. 9, 299 - 306.

TREDOUX, H.G., TRACEY, R.P. \& TROMP, A., 1986. Killer factor in wine yeast and its effect on fermentation. S. Afr. J. Enol. Vitic. 7, $105-112$.

TROMP, A., 1984. The effect of yeast strain, grape solids, nitrogen and temperature on fermentation rate and wine quality. S. Afr. J. Enol. Vitic. 5, $1-6$.

VAN VUUREN, H.J.J. \& WINGFIELD, B.D., 1986. Killer yeasts - Cause of stuck fermentation in a wine cellar. S. Afr. J. Enol. Vitic. 7, $113-118$.

VAUGHAN MARTINI, A. \& KURTZMAN, C.P., 1985. Deoxyribonucleic acid relatedness among species of the genus Saccharomyces sensu stricto. Int. J. System. Bacteriol. 35, 508- 511.

VAUGHAN MARTINI, A. \& MARTINI, A., 1987. Three newly delimited species of Saccharomyces sensu stricto. Antonie van Leeuwenhoek 53, $77-84$.

VOS, P.J.A., ZEEMAN, W. \& HEYMANN, H., 1978. The effect on wine quality of di-ammonium phosphate additions to musts. Proc. S. Afr. Soc. Enol. Vitic. 87-104.

YARROW, D., 1984. Saccharomyces Meyen ex Reess. In: N.J.W. Kreger-van Rij, (ed.) The Yeasts: A Taxonomic Study. Elsevier Science Publisher, Amsterdam. pp 379-395.

ADDENDUM 1

Index of Relationship (R) for all possible combinations of the strains studied.

\begin{tabular}{|l|c|c|c|c|c|c|c|c|c|c|}
\hline & N1 & N2 & N3 & N4 & N5 & N7 & N8 & N9 & N10 & N11 \\
\hline N 1 & 1,000 & 0,904 & 0,970 & 0,943 & 0,848 & 0,942 & 0,946 & 0,952 & 0,760 & 0,899 \\
N 2 & - & 1,000 & 0,910 & 0,914 & 0,835 & 0,877 & 0,910 & 0,932 & 0,833 & 0,818 \\
N 3 & - & - & 1,000 & 0,934 & 0,850 & 0,934 & 0,939 & 0,964 & 0,769 & 0,878 \\
N 4 & - & - & - & 1,000 & 0,820 & 0,936 & 0,972 & 0,948 & 0,778 & 0,867 \\
N 5 & - & - & - & - & 1,000 & 0,811 & 0,822 & 0,835 & 0,885 & 0,830 \\
N 7 & - & - & - & - & - & 1,000 & 0,935 & 0,929 & 0,739 & 0,870 \\
N 8 & - & - & - & - & - & - & 1,000 & 0,952 & 0,767 & 0,864 \\
N 9 & - & - & - & - & - & - & - & 1,000 & 0,787 & 0,863 \\
N10 & - & - & - & - & - & - & - & - & 1,000 & 0,734 \\
N11 & - & - & - & - & - & - & - & - & - & 1,000 \\
\hline
\end{tabular}


ADDENDUM 1

Index of Relationship (R) for all possible combinations of the strains studied.

\begin{tabular}{|c|c|c|c|c|c|c|c|c|c|c|}
\hline & N12 & N13 & N14 & N16 & N17 & N18 & N19 & $\mathbf{N} 23$ & N29 & N71 \\
\hline N 1 & 0,887 & 0,866 & 0,958 & 0,920 & 0,828 & 0,915 & 0,931 & 0,945 & 0,859 & 0,717 \\
\hline N 2 & 0,810 & 0,798 & 0,907 & 0,840 & 0,780 & 0,887 & 0,903 & 0,882 & 0,784 & 0,716 \\
\hline N 3 & 0,873 & 0,855 & 0,968 & 0,903 & 0,839 & 0,921 & 0,937 & 0,957 & 0,840 & 0,719 \\
\hline N 4 & 0,856 & 0,869 & 0,953 & 0,888 & 0,799 & 0,883 & 0,958 & 0,911 & 0,830 & 0,700 \\
\hline N 5 & 0,795 & 0,751 & 0,831 & 0,813 & 0,844 & 0,885 & 0,813 & 0,836 & 0,789 & 0,797 \\
\hline N 7 & 0,861 & 0,876 & 0,951 & 0,890 & 0,794 & 0,879 & 0,949 & 0,910 & 0,832 & 0,685 \\
\hline N 8 & 0,850 & 0,861 & 0,957 & 0,884 & 0,811 & 0,887 & 0,963 & 0,915 & 0,825 & 0,704 \\
\hline N10 & 0,715 & 0,675 & 0,764 & 0,723 & 0,750 & 0,798 & 0,763 & 0,754 & 0,703 & 0,705 \\
\hline N11 & 0,949 & 0,895 & 0,870 & 0,948 & 0,861 & 0,896 & 0,846 & 0,894 & 0,942 & 0,758 \\
\hline N12 & 1,000 & 0,912 & 0,864 & 0,937 & 0,848 & 0,875 & 0,842 & 0,887 & 0,953 & 0,741 \\
\hline N13 & - & 1,000 & 0,861 & 0,911 & 0,790 & 0,830 & 0,861 & 0,857 & 0,894 & 0,689 \\
\hline N14 & - & - & 1,000 & 0,893 & 0,819 & 0,901 & 0,954 & 0,942 & 0,833 & 0,703 \\
\hline N16 & - & - & - & 1,000 & 0,823 & 0,879 & 0,866 & 0,913 & 0,916 & 0,727 \\
\hline N17 & - & - & - & - & 1,000 & 0,868 & 0,798 & 0,859 & 0,864 & 0,829 \\
\hline N18 & - & - & - & - & - & 1,000 & 0,881 & 0,930 & 0,862 & 0,765 \\
\hline N29 & - & - & - & - & - & - & - & - & 1,000 & 0,757 \\
\hline \multirow[t]{2}{*}{ N71 } & - & - & - & - & - & - & - & - & - & 1,000 \\
\hline & N72 & N73 & N77 & N78 & N81 & N83 & N85 & N86 & N87 & N88 \\
\hline N 1 & 0,905 & 0,820 & 0,748 & 0,907 & 0,764 & 0,787 & 0,934 & 0,762 & 0,792 & 0,792 \\
\hline N 2 & 0,880 & 0,756 & 0,817 & 0,940 & 0,825 & 0,827 & 0,875 & 0,823 & 0,786 & 0,814 \\
\hline N 3 & 0,925 & 0,809 & 0,758 & 0,926 & 0,771 & 0,791 & 0,937 & 0,769 & 0,797 & 0,799 \\
\hline N 4 & 0,869 & 0,820 & 0,766 & 0,910 & 0,783 & 0,794 & 0,909 & 0,782 & 0,772 & 0,804 \\
\hline N 5 & 0,825 & 0,729 & 0,728 & 0,852 & 0,886 & 0,889 & 0,865 & 0,874 & 0,915 & 0,904 \\
\hline N 7 & 0,893 & 0,851 & 0,744 & 0,886 & 0,740 & 0,760 & 0,902 & 0,739 & 0,763 & 0,768 \\
\hline N 8 & 0,876 & 0,811 & 0,773 & 0,912 & 0,772 & 0,801 & 0,904 & 0,770 & 0,769 & 0,801 \\
\hline N 9 & 0,909 & 0,801 & 0,771 & 0,941 & 0,788 & 0,803 & 0,925 & 0,787 & 0,786 & 0,817 \\
\hline N10 & 0,740 & 0,654 & 0,813 & 0,808 & 0,963 & 0,932 & 0,785 & 0,948 & 0,851 & 0,929 \\
\hline N11 & 0,884 & 0,857 & 0,673 & 0,834 & 0,736 & 0,750 & 0,925 & 0,735 & 0,806 & 0,766 \\
\hline N12 & 0,842 & 0,878 & 0,664 & 0,828 & 0,718 & 0,725 & 0,906 & 0,715 & 0,780 & 0,746 \\
\hline N13 & 0,823 & 0,931 & 0,667 & 0,797 & 0,678 & 0,686 & 0,854 & 0,677 & 0,741 & 0,704 \\
\hline N14 & 0,903 & 0,819 & 0,769 & 0,916 & 0,764 & 0,784 & 0,926 & 0,764 & 0,780 & 0,793 \\
\hline N18 & 0,913 & 0,784 & 0,728 & 0,901 & 0,799 & 0,818 & 0,954 & 0,798 & 0,852 & 0,826 \\
\hline N19 & 0,884 & 0,827 & 0,761 & 0,909 & 0,765 & 0,786 & 0,904 & 0,764 & 0,763 & 0,794 \\
\hline N23 & 0,937 & 0,813 & 0,748 & 0,920 & 0,754 & 0,771 & 0,951 & 0,752 & 0,807 & 0,780 \\
\hline N29 & 0,809 & 0,867 & 0,642 & 0,797 & 0,705 & 0,715 & 0,888 & 0,703 & 0,771 & 0,736 \\
\hline N71 & 0,718 & 0,677 & 0,596 & 0,724 & 0,725 & 0,717 & 0,746 & 0,731 & 0,825 & 0,748 \\
\hline N72 & 1,000 & 0,803 & 0,745 & 0,908 & 0,740 & 0,756 & 0,902 & 0,738 & 0,798 & 0,766 \\
\hline N73 & - & 1,000 & 0,635 & 0,760 & 0,656 & 0,646 & 0,811 & 0,649 & 0,714 & 0,669 \\
\hline N77 & - & - & 1,000 & 0,798 & 0,800 & 0,814 & 0,719 & 0,800 & 0,710 & 0,779 \\
\hline N78 & - & - & - & 1,000 & 0,808 & 0,825 & 0,891 & 0,807 & 0,801 & 0,832 \\
\hline N81 & - & - & - & - & 1,000 & 0,937 & 0,784 & 0,977 & 0,875 & 0,954 \\
\hline N83 & - & - & - & - & - & 1,000 & 0,789 & 0,941 & 0,849 & 0,932 \\
\hline N85 & - & - & - & - & - & - & 1,000 & 0,783 & 0,832 & 0,813 \\
\hline N86 & - & - & - & - & - & - & - & 1,000 & 0,880 & 0,953 \\
\hline N87 & - & - & - & - & - & $\ldots$ & - & - & 1,000 & 0,903 \\
\hline N88 & - & - & - & - & - & - & - & - & - & 1,000 \\
\hline
\end{tabular}


ADDENDUM 1

Index of Relationship (R) for all possible combinations of the strains studied.

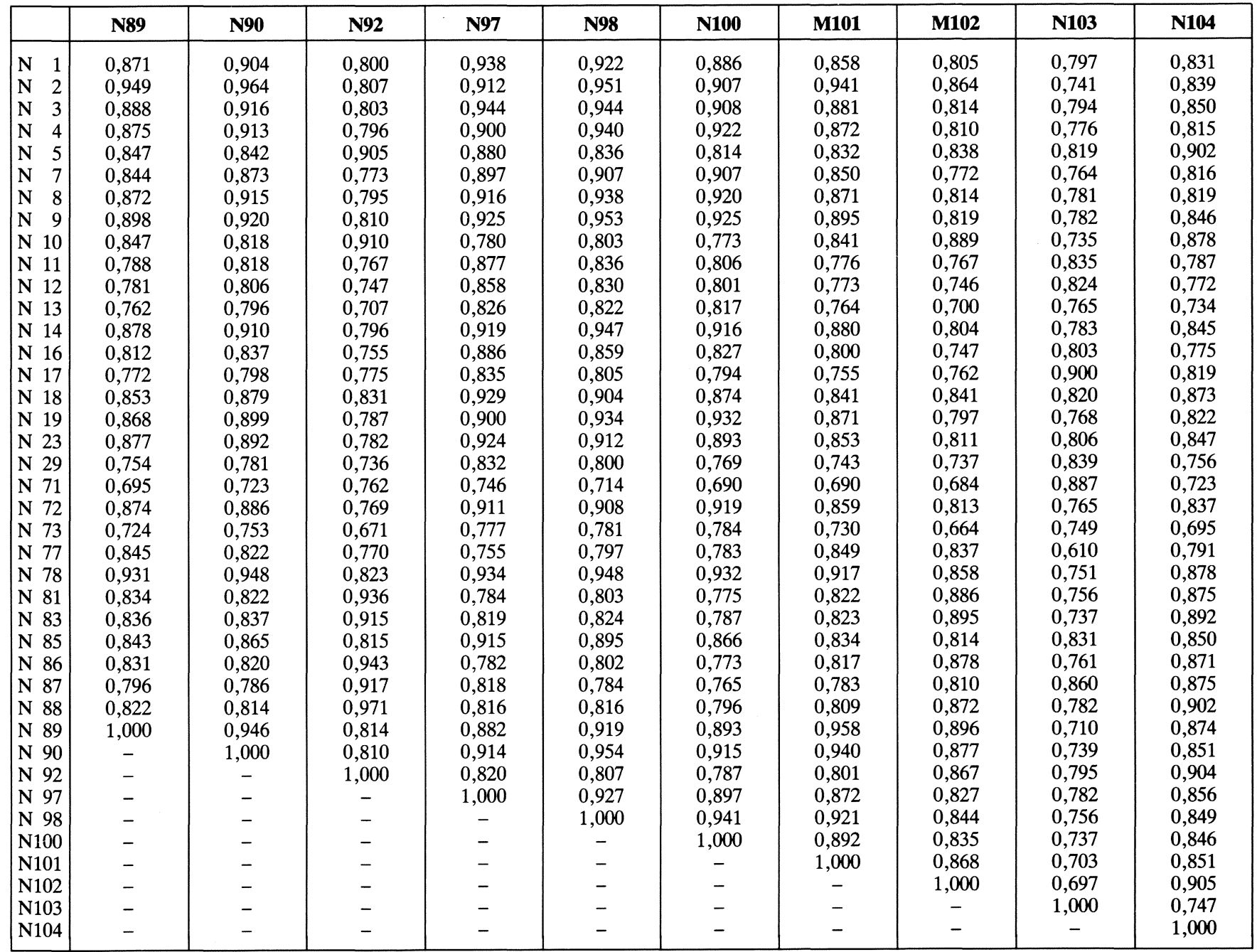


ADDENDUM 1

Index of Relationship (R) for all possible combinations of the strains studied.

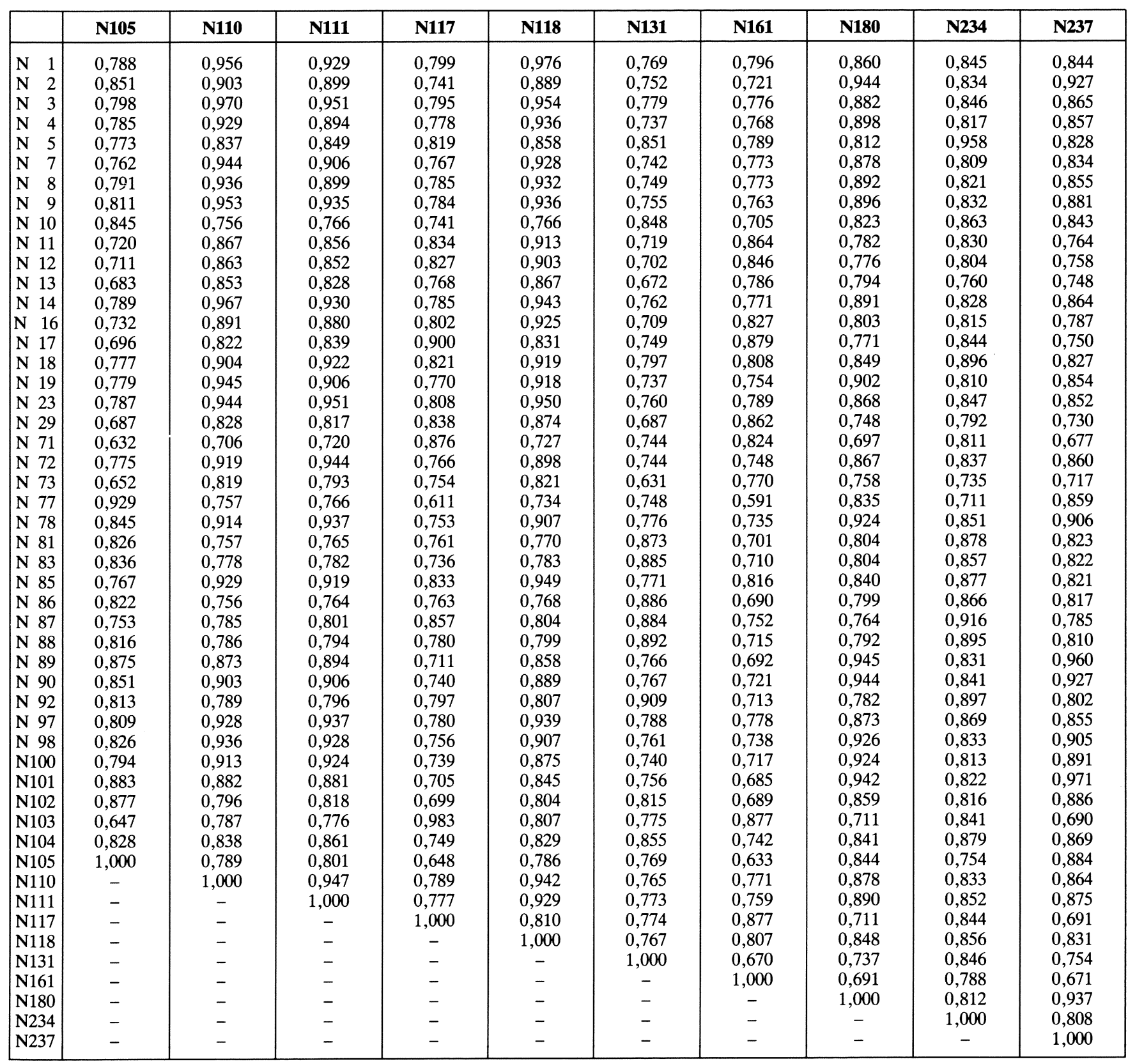

